\title{
COMPARATIVE EFFICACY OF LASER PHOTOCOAGULATION MONOTHERAPY, INTRAVITREAL BEVACIZUMAB MONOTHERAPY AND COMBINED LASER PHOTOCOAGULATION AND INTRAVITREAL BEVACIZUMAB THERAPY IN THE MANAGEMENT OF MACULAR OEDEMA $\geq 350 \mu \mathrm{m}$ IN NON- ISCHAEMIC, NON-PROLIFERATIVE DIABETIC RETINOPATHY IN TYPE 2 DIABETES MELLITUS
}

\author{
Meenu Kashyap¹, Krishnapada Baidya², Tamal Roy³
}

${ }_{1}^{1}$ M.S. Ophthalmology, R.I.O, Kolkata.

${ }^{2}$ Associate Professor, R.I.O Kolkata.

${ }^{3}$ Assistant Professor, Malda Medical College and Hospital, Malda, West Bengal.

ABSTRACT

\section{BACKGROUND}

The purpose of this study is to assess efficacy of laser photocoagulation monotherapy, intravitreal Bevacizumab monotherapy and combined therapy (laser photocoagulation and intravitreal Bevacizumab) on the basis of mean average change in BCVA and changes in macular thickness over 6 months in DME $\geq 350 \mu \mathrm{m}$. This is to identify the best treatment option in Non-Proliferative Diabetic Retinopathy (NPDR) with macular thickness $\geq 350 \mu \mathrm{m}$ in type 2 diabetic retinopathy patients.

Design - An open label, randomised, parallel group, comparative trial.

\section{MATERIALS AND METHODS}

In this study, Best Corrected Visual Acuity (BCVA) and macular thickness (CFT) was compared before and after modified macular grid laser monotherapy, intravitreal Bevacizumab injection monotherapy and combined therapy in patients with macular oedema with thickness $\geq 350 \mu \mathrm{m}$ measured with spectral domain OCT. One hundred and twenty (120) newly diagnosed eyes of NPDR with macular oedema (40 patients in each group, age and sex matched) attending retina clinic of Regional Institute of Ophthalmology, Kolkata, over a period of one year (01/09/2013 to 31/08/2014) were included in this study. Patients having bilateral macular oedema were treated with one group of therapy in one eye and another group of therapy in other eye. We have considered newly diagnosed non-ischaemic non-proliferative diabetic retinopathy eyes with macular oedema of $\geq 350 \mu \mathrm{m}$.

\section{RESULTS}

Mean CFT at the start of the treatment, i.e. the baseline was statistically insignificant in between and within the three groups, but it became significant at 1 month $(\mathrm{p}=0.0001)$, at 3 months $(\mathrm{p}=0.0001)$ and at 6 months $(\mathrm{p}=0.0001)$ using One-Way ANOVA. Therefore, there is significant difference in the improvement achieved at 1 month, 3 months and 6 months in CMT within the three groups and also between the three groups. Mean BCVA at the start of the treatment, i.e. the baseline was statistically insignificant in between and within the three groups, but it became significant at 1 month $(p=0.001)$, at 3 months $(p=0.0001)$ and at 6 months $(p$ $=0.0001$ ) using One-Way ANOVA. Therefore, there is significant difference in the improvement achieved at 1 month, 3 months and 6 months in BCVA.

\section{CONCLUSION}

This parallel group comparative trial has shown that Intravitreal Bevacizumab is most effective in reducing the central macular thickness followed by combined treatment and then modified grid laser treatment. This study has also shown that Intravitreal Bevacizumab is most effective in improving the best corrected visual acuity.

\section{KEYWORDS}

Intravitreal Bevacizumab Monotherapy, Laser Photocoagulation Monotherapy, Combined Therapy, Diabetic Macular Oedema, SDOCT.

HOW TO CITE THIS ARTICLE: Kashyap M, Baidya K, Roy T. Comparative efficacy of laser photocoagulation monotherapy, intravitreal bevacizumab monotherapy and combined laser photocoagulation and intravitreal bevacizumab therapy in the management of macular oedema $\geq 350 \mu \mathrm{m}$ in non-ischaemic, non-proliferative diabetic retinopathy in type 2 diabetes mellitus. J. Evolution Med. Dent. Sci. 2017;6(9):721-726, DOI: 10.14260/Jemds/2017/155

Financial or Other, Competing Interest: None.

Submission 19-12-2016, Peer Review 14-01-2017,

Acceptance 21-01-2017, Published 30-01-2017.

Corresponding Author:

Dr. Tamal Roy,

Premier Residency, Block No. 2,

Flat No. 3A, 236 Briji West,

Near Kancha V.I.P, Garia,

Kolkata-84,

West Bengal.

E-mail: tamal_oph@yahoo.com

DOI: $10.14260 /$ jemds $/ 2017 / 155$

\section{BACKGROUND}

The varying severity of diabetic retinopathy can be classified on the basis of clinical features. Non-proliferative Diabetic Retinopathy (NPDR) refers to presence of intraretinal vascular changes without the presence of extraretinal fibrovascular tissue. In Proliferative Diabetic Retinopathy (PDR), ischaemia-induced neovascularisation from diabetes and the associated complications are noted. The common cause of visual impairment in diabetic retinopathy includes macular oedema and complications due to proliferative retinopathy. Majority of diabetics have type 2 disease, wherein macular oedema is commoner, hence it follows that 
overall macular oedema accounts for more vision impairment than proliferative retinopathy.

The Early Treatment Diabetic Retinopathy Study (ETDRS) ${ }^{1-3}$ demonstrated that focal macular laser reduced the risk of moderate vision loss by up to $50 \%$ in eyes with "clinically significant macular oedema."1-3 Based on three years of follow-up data, ETDRS concluded treatment of center-sparing CSME resulted in only an approximate $45 \%$ decrease in the rate of visual loss. Treatment of center involving CSME resulted in a $67 \%$ decrease in the rate of visual loss. Immediate focal photocoagulation halved the rate of moderate visual loss. In recent years, anti-VEGF ${ }^{4-7}$ emerged as a new approach in the treatment of these devastating diabetic complications.

\section{MATERIALS AND METHODS}

The main outcome measures studied was the change in macular thickness within central subfield ( $1 \mathrm{~mm}$ area) area in SD-OCT at 1 month, 3 months and 6 months in each group of modified grid laser, Inj. Bevacizumab and combined approach. Scores for ETDRS visual acuity were measured at every followup. Those patients who do not respond to the monotherapies (like modified grid laser and Inj. Bevacizumab) were subjected to combined therapy.

All the patients underwent visual acuity assessment by ETDRS chart, Slit-lamp examination of anterior segment, Goldmann applanation tonometry, Direct ophthalmoscope, Indirect ophthalmoscope with +20D lens, Slit-lamp biomicroscopy with +78D lens, Fluorescein fundus angiography (S. No. 1350903, Year - 2007, Topcon Corporation TRC 50EX Japan), Spectral Domain Optical Coherence Tomography (S. No. TSP - 02698, Year - Feb 2011, Heidelberg Engineering Spectralis HRA + OCT).

Patients enrolled for the study had undergone tests like FBS, PPBS, HbA1C, urea, creatinine, complete blood count, lipid profile, blood pressure check-up and cardiological fitness.

Cases were selected on the basis of Inclusion and Exclusion Criteria. The Inclusion Criteria were as follows

1. Patients having non-ischaemic, non-proliferative diabetic retinopathy with macular oedema $(\geq 350 \mu \mathrm{m})$; found within central (1 mm diameter) subfield area in SD - OCT.

2. All diagnosed and well-controlled Type 2 Diabetes Mellitus.

3. Only newly diagnosed cases of NPDR with DME.

4. Not received any form of treatment (grid laser or injection Bevacizumab/any form of intravitreal anti-VEGF or intravitreal triamcinolone injection or any form of intravitreal steroid injection) in the past including posterior sub-tenon steroid injection.

5. Patients having visual acuity $\leq 6 / 12(20 / 40)$, but $>/=$ $3 / 60$ in Snellen's chart or equivalent in ETDRS chart.

6. Coming for the first time for treatment to the Retina Research Clinic and Outpatient Department of Regional Institute of Ophthalmology, Medical College and Hospital, Kolkata and never treated outside also.

7. Age group $>40$ years.

8. Informed consent by the subject.

9. Patients attended for at least 6 months followup.

\section{Exclusion Criteria were as follows}

1. Patients suffering from uncontrolled diabetes mellitus, uncontrolled hypertension, thyroid eye disease, uncontrolled hypercholesterolaemia, anaemia, renal disease or having some other systemic disease, which may affect the retinal thickness as judged by the treating ophthalmologist.

2. Patients having diabetic macular oedema and visual acuity $>/=6 / 12$, but $</=3 / 60$ in Snellen's chart or equivalent in ETDRS chart.

3. Patients with a previous history of prior photocoagulation.

4. Patients who developed complications following laser or intravitreal injection were excluded from study group.

5. Patients having vitreomacular tractions, vitreomacular adhesions, taut posterior hyaloid membrane and vitreous haemorrhages.

6. Patients having central serous retinal detachment.

7. Patients having ischaemic diabetic maculopathy, proliferative diabetic retinopathy.

8. History of ocular trauma.

9. History with evidence of inflammatory eye diseases.

10. Patients having corneal diseases and glaucoma.

11. Patients having any type of optic neuropathy, macular oedema due to other causes, eg:- due to vaso-occlusive diseases, age-related macular degeneration, myopic macular degeneration, any type of pre-existing macular, retinal or choroidal diseases.

12. Patients with dense cataract or other forms of media opacity, which may hamper image capturing by SD-OCT.

13. Poor quality of image due to any reason.

14. Patients who is unable to maintain fixation.

15. Patients with history of or evidence of prior surgery (excepting uncomplicated cataract surgery $>6$ months).

16. Patients with history of or prone to thromboembolic events or cardiovascular disease as determined by the cardiologist.

Patients were randomised either in the modified grid laser monotherapy group or injection Bevacizumab monotherapy group or combined therapy group with modified grid laser therapy and intravitreal bevacizumab.

\section{Spectral Domain Optical Coherence Tomography (SD- OCT)}

The in-built automatic eye tracking technology (TruTrack and tracking laser tomography) in SD-OCT maintains fixation on the retina. The Spectralis mapping software generates automated measures of retinal thickness based on analyses of the central and inner 1000, 3000 and $6000 \mu \mathrm{m}$ subfields as defined by the Early Treatment Diabetic Retinopathy Study. ${ }^{1}$ From this, the central minimum retinal thickness value was recorded as the Minimum Foveal Thickness (MFT) for each scan. Central Foveal Thickness of each retinal layer (CFT), corresponding to the average thickness of all points within the central ETDRS zone of $1000 \mu \mathrm{m}$ diameter was also recorded. For study purpose, we are taking this CFT. Retinal thickness is defined as the distance between the vitreoretinal interface and the inner border of Retinal Pigment Epithelium (RPE). Spectralis OCT includes Bruch's membrane in the retinal thickness measurement. In our study, whenever we use the term macular thickness/CMT it will actually mean the CFT. 


\section{Procedure}

All the procedures were done by a single surgeon.

\section{Modified Grid Laser Monotherapy (Laser) ${ }^{8}$}

Modified grid laser technique employs primarily grid treatment to areas of diffuse leakage with occasional focal treatment of focal leakage located either within or outside the areas of diffuse oedema. ${ }^{9}$ Laser photocoagulation was repeated if the macular thickness is equal to or more than $300 \mu \mathrm{m}$ after 3 months.

\section{Intravitreal Bevacizumab Injection (BVZ)}

The intravitreal injection $(0.05 \mathrm{~mL}$ of $1.25 \mathrm{mg}$ of injection Bevacizumab was loaded into an insulin syringe of 30 gauges size) was repeated at one (1) monthly interval for consecutive 3 months (three) if the macular thickness is equal to or more than $300 \mu \mathrm{m}$ on SD-OCT.

\section{Combined Therapy (BVZ + Laser)}

Here, patients will be given intravitreal Bevacizumab injection first followed by modified grid laser after 4 weeks (four) of intravitreal injection if the macular thickness is equal or more than $300 \mu \mathrm{m}$. Macular thickness in SD-OCT will be compared at 1 month, 3 months and 6 months after the completion of laser procedure. The patients who showed macular oedema $<300$ micron at 1 month in this group was excluded from this group and continued in the $2^{\text {nd }}$ group (Bevacizumab only group).

\section{Followup Care}

Was done to rule out any complication arising due to the procedure.

\section{RESULTS}

\section{Statistical Analysis}

Statistical analysis was done by using descriptive and inferential statistics using Chi square test, One-Way ANOVA and Multiple Comparisons: Tukey Test. The software used in the analysis were SPSS 22.0 and Graph Pad Prism 5.0 and p < 0.05 is considered as level of significance $(p<0.05)$.

In all three groups, maximum cases were in the age group of $51-60$ yrs. Age distribution in the three groups was statistically non-significant $(p=0.49)$ and also gender wise distribution of three groups were statistically non-significant $(\mathrm{p}=0.29)$.

Multiple comparisons within and between the three groups using One-Way ANOVA ( $p$ valve $=0.097$ ) and Tukey test ( $p$ value for BVZ and laser was 0.131). Similarly, between BVZ and BVZ + laser it was 0.993 and between laser and BVZ + laser it was 0.164 , shows that the variation in the baseline CMT for the three groups were statistically insignificant.

Multiple comparisons within and between the three groups using One-Way ANOVA ( $\mathrm{p}$ valve $=0.869$ ) and Tukey test ( $p$ value for BVZ and laser was 0.857 . Similarly, between BVZ and BVZ + laser it was 0.952 and between laser and BVZ + laser it was 0.971 , show that the variation in the baseline BCVA for the three groups were statistically insignificant.

At 1 month, mean CFT in BVZ group decreased from baseline of $406.55 \pm 28.98 \mu \mathrm{m}$ to $340.05 \pm 26.98 \mu \mathrm{m}$, a difference of $66.50 \mu \mathrm{m} \pm 10.20 \mu \mathrm{m}(\mathrm{P}=0.0001)$ and this overall improvement continued at the 3 - and 6-month time points. At 3- and 6-month follow-ups, mean central macular thicknesses were $291.00 \pm 21.48 \mu \mathrm{m}$ and $269.57 \pm 12.40 \mu \mathrm{m}$ respectively with $\mathrm{p}$ value $=0.0001$.

There was statistically significant improvement at 1 month, 3 months and 6 months CFT with intravitreal injection Bevacizumab when compared with baseline $(\mathrm{p}=$ .0001).

\section{The Proportion of Eyes that were Retreated during the 6 Months of Followup was}

$40(100 \%)$ were retreated with $2^{\text {nd }}$ injection and $15(37.5 \%)$ were retreated with $3^{\text {rd }}$ injection.

Mean BCVA measurements in the group BVZ at baseline, 1 month, 3 months and 6 months were $1.07 \pm 0.32$ (Log MAR), $0.87 \pm 0.19(\log M A R), 0.78 \pm 0.15(\log M A R)$ and $0.69 \pm 0.23$ (Log MAR) respectively.

Using the student's paired ' $t$ ' test, $p$ value for patients receiving intravitreal injection BVZ compared for BCVA at 1 month, 3 months and 6 months was statistically significant ( $p$ $=0.0001$ ). There was significant improvement in BCVA in patients treated with intravitreal Bevacizumab at 1 month, 3 months and 6 months BCVA when compared with Baseline.

At 1 month, 60\% patients had improvement in BCVA as compared to baseline. On subsequent followup, 65\% patients had improvement at 3 months over 1 month BCVA and 70\% had improvement at 6 months when compared to 3 months. There was deterioration in 5\% patients BCVA receiving intravitreal bevacizumab at 6 months.

The foveal thickness improved on followup at 1 month, 3 months and 6 months after modified grid laser treatment. At 1 month, mean CFT decreased from baseline of $394.90 \mu \mathrm{m} \pm$ $24.23 \mu \mathrm{m}$ to $368.17 \pm 45.81 \mu \mathrm{m}$, a difference of $26.72 \mu \mathrm{m}(\mathrm{P}=$ 0.0001), and this overall improvement continued at the 3rd and 6-month time points. At 3 and 6 months follow-up, mean central macular thicknesses were $349.82 \mu \mathrm{m} \pm 44.93 \mu \mathrm{m}$ and $332.95 \mu \mathrm{m} \pm 56.74 \mu \mathrm{m}$ respectively with a p value of 0.0001 .

There was statistically significant improvement at 1 month, 3 months and 6 months CFT with modified grid laser when compared with baseline $(\mathrm{p}=.0001)$.

$34(85 \%)$ patients were retreated $2^{\text {nd }}$ time with modified grid laser treatment at 3 months, while 6 (15\%) had never received treatment twice.

$70 \%$ patients had improvement in foveal thickness at 1 month when compared with baseline. Similarly, $82.5 \%$ patients had improvement in foveal thickness at 3 months when compared with values at 1 month. At 6 months, $67.5 \%$ of patients had decrease in foveal thickness when compared to 3-month values. Rest showed increase in foveal thickness.

In modified grid laser group using the Student's paired ' $\mathrm{t}$ ' test, $\mathrm{p}$ value for laser, BCVA at 1 month, 3 months and 6 months was statistically insignificant with $\mathrm{p}=0.570, \mathrm{p}=$ 0.273 and $p=0.523$ respectively when compared with baseline.

Hence, there was no significant improvement in BCVA with modified grid laser treatment at 1 month, 3 months and 6 months BCVA when compared with baseline.

$12.5 \%$ patients had improvement in BCVA, whereas $70 \%$ patients had no change in BCVA and $17.5 \%$ had deterioration in BCVA at 1 month when compared with baseline. At 3 months, only $10 \%$ had improvement in CFT when compared with 1 month. Similarly, only $10 \%$ had improvement at 6 months when compared with 3 months. 
The CFT improved on followup at 1 month, 3 months and 6 months after combination treatment. At 1 month, mean CFT decreased from baseline of $405.87 \pm 26.97 \mu \mathrm{m}$ to $343.82 \pm$ $24.26 \mu \mathrm{m}$, a difference of $61.44 \mu \mathrm{m}(\mathrm{P}=0.0001)$ and this overall improvement continued at the 3- and 6-month time points. At 3- and 6-month follow-up, mean central CFT were $326.30 \pm 39.01 \mu \mathrm{m}$ and $299.52 \pm 36.51 \mu \mathrm{m}$ respectively with a $\mathrm{p}$ value of 0.0001 .

There was statistically significant improvement at 1 month, 3 months and 6 months CFT with BVZ + modified grid laser when compared with baseline $(p=0.0001)$.

The Proportion of Eyes that were retreated during 6 Months of followup was

$40(100 \%)$ were retreated with modified grid laser at 1 month and $29(72.5 \%)$ were retreated with repeat modified grid laser at 3 months.

In combination treatment group using the Student's paired ' $\mathrm{t}$ ' test $\mathrm{p}$ value for BVZ + laser BCVA at 1 month, 3 months and 6 months was statistically significant with $\mathrm{p}=$ 0.0001 when compared with baseline.

Hence, there was significant improvement in BCVA with combined treatment at 1 month, 3 months and 6 months BCVA when compared with baseline.

$70 \%$ patients had improvement in BCVA at 1 month, whereas $30 \%$ had no change in BCVA at 1 month when compared with baseline. At 3 months, only $10 \%$ had improvement in BCVA when compared with 1 month. Similarly, only $10 \%$ had improvement at 6 months when compared with 3 months.

\begin{tabular}{|c|c|c|c|c|c|c|c|}
\hline \begin{tabular}{|c|c} 
Time \\
Interval
\end{tabular} & Group & $\mathbf{N}$ & Mean & $\begin{array}{c}\text { Std. } \\
\text { Devia- } \\
\text { tion }\end{array}$ & \begin{tabular}{c|} 
Std. \\
Error
\end{tabular} & Mini & Max \\
\hline \multirow{3}{*}{$\begin{array}{l}\text { Base- } \\
\text { line }\end{array}$} & BVZ & 0 & 5 & 28.98 & \begin{tabular}{|l|}
4.58 \\
\end{tabular} & 362.00 & 49.0 \\
\hline & Laser & 40 & 4.90 & 24.23 & \begin{tabular}{|l|}
3.83 \\
\end{tabular} & 355.00 & 149.00 \\
\hline & $\begin{array}{ll}\text { BVZ+ } \\
\text { Laser }\end{array}$ & 40 & 405.87 & 26.97 & 4.26 & 362.00 & 449.00 \\
\hline \multirow{3}{*}{$\begin{array}{c}1 \\
\text { month }\end{array}$} & BVZ & 40 & 40.05 & 26.98 & 4.26 & 302.00 & 384.00 \\
\hline & Laser & 40 & 368.17 & 45.81 & 7.24 & 294.00 & 449.00 \\
\hline & $\begin{array}{l}\text { BVZ+ } \\
\text { Laser }\end{array}$ & 40 & 2 & .26 & 3.83 & 303.00 & 381.00 \\
\hline \multirow{3}{*}{$\begin{array}{c}3 \\
\text { months }\end{array}$} & BVZ & & 91.00 & 21.48 & | & 259.00 & 350.00 \\
\hline & Laser & ) & 49.82 & 44.93 & 7.10 & 271.00 & 440.00 \\
\hline & $\begin{array}{l}\text { BVZ+ } \\
\text { Laser }\end{array}$ & 40 & 326.30 & 39.01 & 6.16 & 270.00 & 416.00 \\
\hline \multirow{3}{*}{$\begin{array}{c}6 \\
\text { months }\end{array}$} & BVZ & 40 & 269.57 & 12.40 & 1.96 & 242.00 & 291.00 \\
\hline & Laser & 40 & 332.95 & 56.74 & 8.97 & 231.00 & 444.00 \\
\hline & $\begin{array}{c}\text { BVZ+La } \\
\text { ser }\end{array}$ & 40 & 299.52 & 36.31 & 5.74 & 252.00 & 398.00 \\
\hline \multicolumn{8}{|c|}{$\begin{array}{l}\text { Table 1. Comparison of CFT in Three Groups } \\
\text { at Baseline, } 1 \text { Month, } 3 \text { Months and } 6 \text { Months }\end{array}$} \\
\hline
\end{tabular}

Mean CFT at the start of the treatment, i.e. the baseline was statistically insignificant in between and within the three groups, but it became significant at 1 month ( $p=0.0001)$, at 3 months $(p=0.0001)$ and at 6 months $(p=0.0001)$ using OneWay ANOVA. Therefore, there is significant difference in the improvement achieved at 1 month, 3 months and 6 months in CMT within the three groups and also between the three groups.

There was no significant difference in the baseline CFT between the three groups. At 1 month, Tukey test shows on comparison between BVZ and laser group and between laser and combined group the $p$ value is 0.001 and 0.005 which is statistically significant. But in BVZ and BVZ + laser group it was statistically insignificant ( $\mathrm{p}=0.871$ ).

Similarly, the comparison between BVZ and laser is statistically significant at 3 months and 6 months $(p=0.000)$.

At 3 and 6 months, the comparison between BVZ and BVZ + laser group is also statistically significant with $\mathrm{p}$ valve of 0.000 and 0.003 respectively.

At 3 and 6 months, the comparison between laser and combined is also statistically significant with p value of 0.013 and 0.001 respectively.

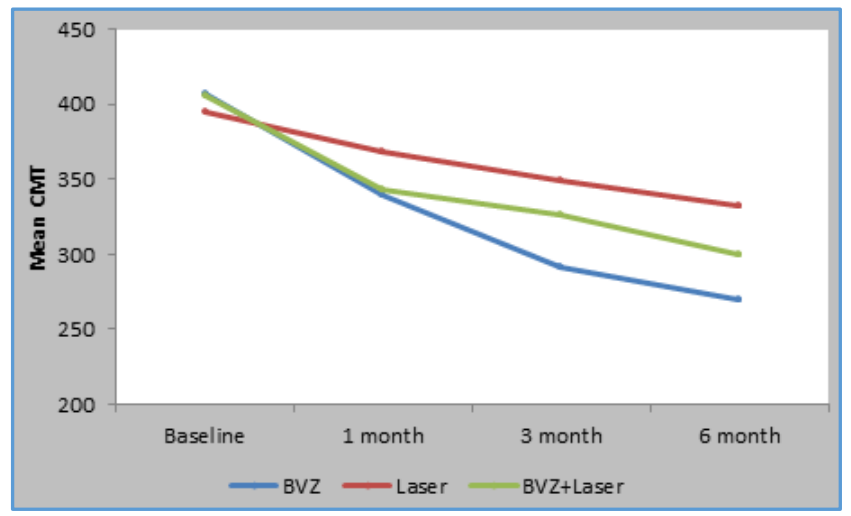

Diagram 1

\begin{tabular}{|c|c|c|c|}
\hline & BVZ & Laser & BVZ + Laser \\
\hline 1 month & $16.35 \%$ & $6.76 \%$ & $15.28 \%$ \\
\hline 3 months & $28.42 \%$ & $11.41 \%$ & $19.60 \%$ \\
\hline 6 months & $33.69 \%$ & $15.68 \%$ & $26.20 \%$ \\
\hline
\end{tabular}

Table 2. Percentage of Improvement in Three Groups in CFT from Baseline

As per the Table 2, there was maximum improvement in patients receiving $\mathrm{BVZ}$ as compared to laser and $\mathrm{BVZ}+$ laser.

\section{Descriptive Statistics}

\begin{tabular}{|c|c|c|c|c|c|c|c|}
\hline $\begin{array}{c}\text { Time } \\
\text { Interval }\end{array}$ & Group & $\mathbf{N}$ & Mean & $\begin{array}{c}\text { Std. } \\
\text { Devia- } \\
\text { tion }\end{array}$ & $\begin{array}{c}\text { Std. } \\
\text { Error }\end{array}$ & Min & Max \\
\hline \multirow{3}{*}{ Baseline } & BVZ & 40 & 1.07 & 0.32 & 0.05 & 0.60 & 1.78 \\
\hline & Laser & 40 & 1.04 & 0.14 & 0.02 & 0.82 & 1.32 \\
\hline & $\begin{array}{l}\text { BVZ+ } \\
\text { Laser }\end{array}$ & 40 & 1.06 & 0.22 & 0.03 & 0.72 & 1.90 \\
\hline \multirow{3}{*}{1 month } & BVZ & 40 & 0.87 & 0.19 & 0.03 & 0.60 & 1.78 \\
\hline & Laser & 40 & 1.04 & 0.15 & 0.02 & 0.62 & 1.32 \\
\hline & $\begin{array}{l}\text { BVZ+ } \\
\text { Laser }\end{array}$ & 40 & 0.94 & 0.21 & 0.03 & 0.62 & 1.90 \\
\hline \multirow{3}{*}{$\begin{array}{c}3 \\
\text { months }\end{array}$} & BVZ & 40 & 0.78 & 0.15 & 0.02 & 0.50 & 1.30 \\
\hline & Laser & 40 & 1.06 & 0.16 & 0.02 & 0.82 & 1.62 \\
\hline & $\begin{array}{l}\text { BVZ+ } \\
\text { Laser }\end{array}$ & 40 & 0.96 & 0.22 & 0.03 & 0.52 & 1.90 \\
\hline \multirow{3}{*}{$\begin{array}{c}6 \\
\text { months }\end{array}$} & BVZ & 40 & 0.69 & 0.23 & 0.03 & 0.40 & 1.78 \\
\hline & Laser & 40 & 1.05 & 0.15 & 0.02 & 0.62 & 1.32 \\
\hline & BVZ+Laser & 40 & 0.96 & 0.23 & 0.03 & 0.62 & 1.90 \\
\hline
\end{tabular}


It shows mean, standard deviation and standard error of BCVA at baseline, 1 month, 3 months and 6 months in three groups.

Mean BCVA at the start of the treatment, i.e. the baseline was statistically insignificant in between and within the three groups, but it became significant at 1 month ( $p=0.001)$, at 3 months $(p=0.0001)$ and at 6 months $(p=0.0001)$ using OneWay ANOVA. Therefore, there is significant difference in the improvement achieved at 1 month, 3 months and 6 months in BCVA within and between the three groups.

There was no significant difference in the baseline BCVA between the three groups. At 1 month, Tukey test shows on comparison between BVZ and combined group and between laser and combined group the $\mathrm{p}$ value is 0.188 and 0.082 which is statistically insignificant. But BVZ and laser group, it was statistically significant $(p=0.0001)$.

Similarly, the comparison between BVZ and laser is statistically significant at 3 months and 6 months $(\mathrm{p}=$ 0.0001).

At 3 and 6 months, the comparison between BVZ and BVZ + laser group is also statistically significant with $p$ value of 0.001 .

At 3 and 6 months, the comparison between laser and combined is statistically insignificant with $\mathrm{p}$ value of 0.054 and 0.124 respectively.

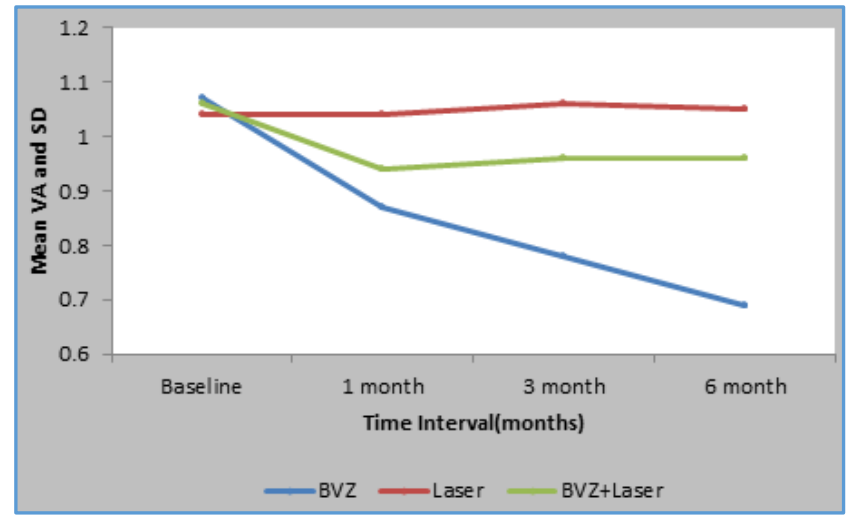

Diagram 2

Comparison of VA in three groups at 1 month, 3 months and 6 months.

Percentage of improvement in three groups in VA from baseline.

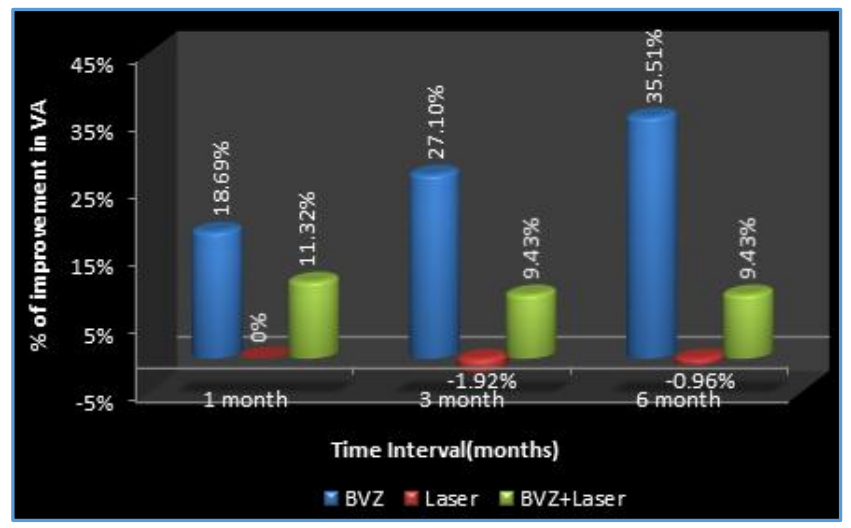

Diagram 3
Patients receiving intravitreal bevacizumab had the most improvement in BCVA.

\section{DISCUSSION}

Throughout the study, the sugar levels of the patients were under control. There was no associated hypertension or lipid profile abnormalities in any of the patient. These factors are also known to play a role in macular oedema.

In Group 1 of Intravitreal Bevacizumab $(0.05 \mathrm{~mL} / 1.25$ $\mathrm{mg}$ ), the mean baseline CMT was $406.55 \pm 28.98 \mu \mathrm{m}$, which was decreased to mean $269.57 \pm 12.40 \mu \mathrm{m}$ at 6 months. The difference in mean was found to be $136.98 \mu \mathrm{m}$. Hence, there was statistical significant reduction in CMT at the end of the study and also at all the followup months ( $p$ value $\leq 0.001$ ); $2^{\text {nd }}$ and $3^{\text {rd }}$ dose of intravitreal injection were given to patients having macular oedema $\geq 300 \mu \mathrm{m}$ at $1^{\text {st }}$ and $2^{\text {nd }}$ month of followup. The baseline mean BCVA was $1.07 \pm 0.32$ Log MAR, which was improved to $0.69 \pm 0.23$ Log MAR at 6 months. Improvement at all the followup was statistically significant in BCVA when compared to baseline ( $p=0.0001)$.

In Group 2 of modified grid laser treatment, the mean baseline CMT was $394.90 \pm 24.23 \mu \mathrm{m}$, which was decreased to mean $332.95 \pm 56.74 \mu \mathrm{m}$ at 6 months. The difference in mean was found to be $61.95 \mu \mathrm{m}$ with baseline. Hence, there was statistical significant reduction in CMT at the end of the study and also at all the followup months ( $p \leq 0.001$ ). Modified grid laser treatment was performed twice in patients who had macular oedema $\geq 300 \mu \mathrm{m}$ at their 3 months followup. The baseline mean BCVA was $1.04 \pm 0.14$ Log MAR, which remain similar to mean 1.05 \pm 0.15 Log MAR at 6 months. Hence, there was no improvement noticed in BCVA with Modified Grid Laser treatment at the end of the study ( $\mathrm{p}=0.523)$.

In Group 3 of combined treatment with intravitreal Bevacizumab and modified grid laser treatment, the mean baseline CMT was $405.87 \pm 26.97 \mu \mathrm{m}$, which was decreased to mean $299.52 \pm 36.51 \mu \mathrm{m}$ at 6 months. The difference in mean was found to be $106.35 \mu \mathrm{m}$ with baseline. Hence, there was statistical significant reduction in CMT at the end of the study and also at all the followup months ( $p \leq 0.001)$. All the patients received intravitreal Bevacizumab injection first followed by modified grid laser after 1 month of intravitreal injection with the macular thickness $\geq 300 \mu \mathrm{m}$. The baseline mean BCVA was $1.06 \pm 0.22 \mathrm{Log}$ MAR, which was improved to mean $0.96 \pm 0.23$ Log MAR at 6 months. There was statistical improvement noticed in BCVA with combined therapy at every followup and at the end of the study.

Intravitreal Bevacizumab $(0.05 \mathrm{~mL} / 1.25 \mathrm{mg})$ was given to all the enrolled patients under full aseptic conditions. No complications like endophthalmitis, uveitis, raised intraocular pressure, cataractous lens due to injury to lens by needle (30G), iatrogenic retinal breaks, vitreous haemorrhage and retinal detachment were seen in the course of the study in any patient who received intravitreal injection.

2 patients of modified grid laser group only complained of distorted visual images due to laser burns, but it was found to be in parafoveal area and did not affect the BCVA of the patients. However, other complications like photocoagulation of fovea, haemorrhage, choroidal neovascular membrane or macular hole were never noticed till the end of the study.

When the three groups were compared, the mean CFT reduction of Inj. Bevacizumab group, combined group and 
modified grid laser treatment group was $136.98 \mu \mathrm{m}, 106.35$ $\mu \mathrm{m}, 61.95 \mu \mathrm{m}$ with their baseline respectively. Out of 40,38 patients showed decrease and 2 patients showed increase in CMT in Inj. Bevacizumab group. Out of 40, 39 patients showed decrease in CMT and 1 patient remained stable in combined group. Out of forty 22 patients showed decrease, 18 patients remained stable and 3 patients showed increase in CMT in modified grid laser treatment group. Baseline mean BCVA of 40 patients in each of Inj. Bevacizumab group and combined group was improved to mean of $0.69 \pm 0.23 \mathrm{Log}$ MAR and $0.96 \pm 0.23$ Log MAR respectively at 6 months. But baseline mean BCVA of 40 patients of modified grid laser treatment remained similar (1.05 $\pm 0.15 \mathrm{Log}$ MAR) at the end of 6 months. Out of 40,38 patients showed improvement and 2 patients showed deterioration in BCVA in Inj. Bevacizumab group, the reason being found to be macular ischaemia. Out of forty, 20 patients had improvement, 18 remained stable and only 2 patients had decreased in their BCVA from baseline in combined group. Out of forty, 8 patients were improved, 28 remained stable and only 4 had decreased in their BCVA in modified grid laser treatment group.

At 1-month the percentage wise improvement in CMT over baseline in injection Bevacizumab group, combined group and modified grid laser treatment group was $16.35 \%$, $15.28 \%$ and $6.76 \%$ respectively. At 3 months, the percentage wise improvement over baseline in CMT in injection Bevacizumab group, combined group and modified grid laser treatment group was $28.42 \%, 19.60 \%$ and $11.41 \%$ respectively. At 6 months, the percentage wise improvement in CMT over baseline in injection Bevacizumab group, combined group and modified grid laser treatment group was $33.69 \%, 26.20 \%$ and $15.68 \%$ respectively. Similarly, at 1 month percentage wise improvement in BCVA over baseline in injection Bevacizumab group, combined group and modified grid laser treatment group was $18.69 \%, 11.32 \%$ and $0 \%$ respectively. At 3 months, the percentage wise improvement in BCVA over baseline in injection Bevacizumab group, combined group and modified grid laser treatment group was $27.10 \%, 9.43 \%$ and $-1.92 \%$ respectively. At 6 months, the percentage wise improvement in BCVA over baseline in injection Bevacizumab group, combined group and modified grid laser treatment group was 35.51\%, 9.44\% and $-0.96 \%$ respectively.

\section{CONCLUSION}

This parallel group comparative trial has shown that Intravitreal Bevacizumab is most effective in reducing the central macular thickness followed by combined treatment and then modified grid laser treatment. This study has also shown that Intravitreal Bevacizumab is most effective in improving the best corrected visual acuity, whereas there is very less improvement in best corrected visual acuity in combined treatment and no improvement was noted in best corrected visual acuity in modified laser group.

\section{REFERENCES}

[1] Photocoagulation for diabetic macular edema. Early treatment diabetic retinopathy study report number 1 early treatment diabetic retinopathy study research group. Arch Ophthalmology 1985;103(12):1796-806.

[2] Early treatment diabetic retinopathy study research group. Early photocoagulation for diabetic retinopathy. ETDRS report number 9. Ophthalmology 1991;98(5 Suppl):766-85.

[3] Early treatment diabetic retinopathy study research group. Focal photocoagulation treatment of diabetic macular edema. Relationship of treatment effect to fluorescein angiographic and other retinal characteristics at baseline. ETDRS report number 19. Arch Ophthalmol 1995;113(9):1144-55.

[4] Spaide RF, Fisher YL. Intravitreal bevacizumab (Avastin) treatment of proliferative diabetic retinopathy complicated by vitreous haemorrhage. Retina 2006;26(3):275-8.

[5] Adamis AP, Miller JW, Bernal MT, et al. Increased vascular endothelial growth levels in the vitreous with eyes with proliferative diabetic retinopathy. Am J Ophthalmos 1994;118(4):445-50.

[6] Aiello LP, Avery RL, Arrigg PG, et al. VEGF in ocular fluids of patients with diabetic retinopathy and other retinal disorders. N Engl J Med 1994;331(22):1480-7.

[7] Lebherz C, Maguire AM, Auricchio A, et al. Nonhuman primate models for diabetic ocular neovascularization using AAV2-mediated overexpression of VEGF. Diabetes 2005;54(4):1141-9.

[8] Dandona L, Dandona R, Naduvilath TJ, et al. Population based assessment of diabetic retinopathy in an urban population in southern India. $\mathrm{Br} \mathrm{J}$ Ophthalmol 1999;83(8):937-40.

[9] Rema M, Premkumar S, Anitha B, et al. Prevalance of diabetic retinopathy in urban India: the Chennai urban rural epidemiology study (CURES) eye study, I. Invest Ophthalmol Vis Sci 2005;46(7):2328-33. 